\title{
Numerical modeling of the contact effect on the parameters of cracking in a 2D Fatigue Fretting Model
}

\author{
Mohammed Bentahar \\ Faculty of Technology, University Tahar Moulay, Saida, Laboratoire LABAB, ENP Maurice Audin, Oran, Algeria \\ bentahae@yahoo.fr \\ Habib Benzaama \\ National Polytechnic School of Oran M.A., ENPO, Laboratoire LABAB, ENP Maurice Audin, Oran, Algeria \\ habenza@yahoo.fr \\ Mahmoudi Noureddin \\ Faculty of Technology, University Tahar Moulay, Saida, Laboratory GIDD, University of Relisane, Algeria \\ mahmoudi.noureddine@yahoo.fr
}

\begin{abstract}
The objective of this work is to study the effects of contact parameters on the cracking parameters of a specimen and a pad assembly. These parameters have been studied and evaluated by the finite element method analysis in two dimensions fretting fatigue model through the Abaqus calculation code. Different values of the coefficient of friction of $0.1,0.3$ and 0.6 were applied on the various lengths in contact for $\mathrm{a}=0.1,0.5$ and $1 \mathrm{~mm}$. Thus, on the various values of angle of orientation of the crack equal to $15^{\circ}$, $30^{\circ}$ and $45^{\circ}$. In addition, elements of the type (CPE4R) and the criterion of maximum tangential stress were applied. The curves of the crack parameters such as the SIF coefficients and the integral J were obtained and discussed.
\end{abstract}

KEYwORDS: 2D crack; FEM; Fretting fatigue; Stress intensity factor (SIF); Coefficient of friction (COF).

\section{OPEN ACCESS}

Citation: Bentahar, M., Benzaama, H., Mahmoudi, N., Numerical modeling of the contact effect on the parameters of cracking in a $2 \mathrm{D}$ Fatigue Fretting Model,Frattura ed Integrità Strutturale, 57 (2021) 182-194.

Received: 16.04 .2021

Accepted: 05.06.2021

Published: 01.07.2021

Copyright: (C) 2021 This is an open access article under the terms of the CC-BY 4.0, which permits unrestricted use, distribution, and reproduction in any medium, provided the original author and source are credited.

\section{INTRODUCTION}

$\mathrm{F}$

retting fatigue is a mechanical phenomenon of damage that occurs between two assembled parts (a test tube and a pad), under a contact load and in the presence of repeated oscillatory or relative surface movement. Indeed, several studies have been proposed in the literature to model the problems in fretting fatigue, among these studies we cite the work of Kyvia et al [1] treated the different aspects related to the modeling of fretting fatigue by the FEM method, to present common experimental setups and analytical solutions for thecylindrical contact. Another numerical method used by Hojjati et al [2] to predict both sides the initiation phase and the crack propagation. Thus, to estimate the fracture life by fretting fatigue under a conforming contact configuration. Julien et al [3] studied the propagation of fretting fatigue cracks by the use of 
the FEM method, to simulate and deduce the distributions of the stress intensity factor (SIF) in the length of the crack front.

Thanh et al [4] proposed a new approach based on the evaluation of nucleation, and the lifetime of deterioration due to fretting fatigue, to measure the change of the central point of the power spectral density (CP -PSD). In addition, Nadeem Ali Bhatti, and Abdel Wahab [5] used three numerical models in fretting fatigue, to model the effect of in-phase and out-of-phase loads on contact stresses and damage initiation locations. Qingmingetal [6] used the finite element method (FEM), for different sizes, shapes and properties of inclusions, to study and analyze the effects of randomly distributed micro-inclusions on the fretting fatigue behavior of heterogeneous materials. Antti et al [7] presented a robust wear simulation method, based on the finite element method, and adapted to contact friction. Tongyan and Abdel Wahab [8] used the finite element method (FEM) to study the evolution of contact variables and wear scars during the wear process by friction. Antti et al [9] to assess the risk of friction in the large end performed a detailed contact analysis of a large connecting rod. Jouko et al [10] studied the role of wear particle movements under axisymmetric loading conditions, of a flat on flat annular contact in a self-coupled hardened and tempered steel material. Wijesuriya and Mallikarachchi [11] evaluated finite element models and analytical techniques for fatigue fretting crack propagation. Wang and Abdel Wahab [12] analyzed the wear characteristics in partial slip regime on the effects of loading conditions in fretting fatigue. Chen et al [13] studied by the finite element method the initiation and growth of fretting fatigue cracks, In addition, they calculated the contact stress, to know the crack initiation angle by the criterion (MTS). Nitikornet al [14] carried out finite element fatigue fretting experiments, to study the influence of cylindrical contact on plate and on crack nucleation.

The goal of this study is to model the effect of the variation of the coefficient of friction, on the parameters of cracking. More precisely, on the evaluation of the stress intensity factor in mode I and the contour integral J for a model in homogeneous material with linear and isotropic elastic behavior.This problem is studied in fretting fatigue, two cases of crack were studied with different positions, one of horizontal crack of angle $\alpha=0^{\circ}$ and another case of an inclined crack of $\alpha=15,30$ and $45^{\circ}$.

\section{CRACK MODELIZATION}

\section{Maximum tangential stress criterion}

7 his criterion, introduced by Erdogan and Sih [15] for elastic materials, indicates that the crack propagates in the direction for which the circumferential stress $\sigma_{\theta \theta}$ is maximum, it is a local approach since the direction of the crack growth is directly determined by the local stress field. According to this criterion, the growth of the crack follows the direction of $\left(\theta=\theta_{0}\right)$ which is perpendicular to the tangent of maximum stress. The angle of deviation of the crack $\theta_{0}$ can be obtained by:

$$
\begin{aligned}
& \left.\sigma_{\theta \theta}\right|_{\theta=\theta_{0}}>0,\left.\frac{\partial \sigma_{\theta \theta}}{\partial \theta}\right|_{\theta=\theta_{0}}=0 \quad \text { and }\left.\quad \frac{\partial^{2} \sigma_{\theta \theta}}{\partial \theta^{2}}\right|_{\theta=\theta_{0}}<0 \\
& \sigma_{\theta \theta}=\frac{1}{4 \sqrt{2 \pi}}\left[K_{I}\left(\cos \frac{\theta}{2}+\cos \frac{3 \theta}{2}\right)-3 K_{I I}\left(\sin \frac{\theta}{2}+\sin \frac{3 \theta}{2}\right)\right]
\end{aligned}
$$

We can deduce:

$$
K_{I} \sin \theta+K_{I I}(3 \cos \theta-1)=0
$$

So, we have: 


$$
\tan \left(\frac{\theta}{2}\right)=\frac{1}{4}\left(\frac{K_{I}}{K_{I I}}\right) \pm \frac{1}{4} \sqrt{\left(\frac{K_{I}}{K_{I I}}\right)^{2}+8}
$$

$\theta$ gives the direction of the maximum of the circumferential stress which determines the angle of bifurcation.

\section{Different parameters to characterize the singular zone}

The characterization of the singular zone subjected to several essential parameters, which makes it possible to study this zone such as, the stress intensity factor $\mathrm{K}$ and the integral of the contour $\mathrm{J}$.

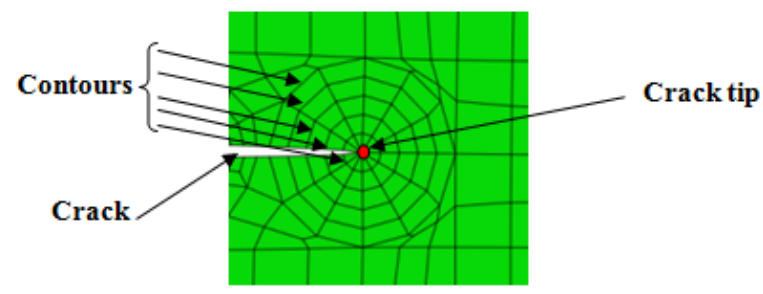

Figure 1: Singular zone meshing

Stress intensity factor

Saverio [16] defined the stress intensity factor K, which is the only significant parameter, which allows to know the state of stress and strain at any crack point.

$$
K_{I}=F \sigma \sqrt{a} \pi
$$

where, $\mathrm{F}$ is the geometric correction factor of the model used.

$$
F=1.12-0.23(a / w)+10.6(a / \mathrm{w})^{2}-21.7(a / \mathrm{w})^{3}+30.4(a / \mathrm{w})^{4}
$$

where the stress intensity factor $\mathrm{K}_{\mathrm{II}}$ is calculated by the relation.

$$
K_{I} \sin \theta+K_{I I}(3 \cos -1)=0
$$

\section{Contour Integral J}

Several authors in fracture mechanics have allowed to model the problem of the presence of a crack in an indepth way and have developed the calculation methods. Among these authors Rice [17] and Bui [18] with contour integrals (J), Nguyen [19] and Destuynder [20] by introducing an arbitrary field in the formulation of the integral they have approached. Indeed, work has been developed on the basis of elasticity in small displacements and mainly addresses the first phase of the cracking process.

\section{Relation betweenK and Jparameters}

In the fracture mechanics, we have two Eqns. (8) and (9) which allow to assemble the two parameters one obtains according to Tran [21]:

$$
\begin{gathered}
-\frac{d P}{d a}=J_{I}=\frac{1-v}{E} K_{I}^{2} \\
-\frac{d P}{d a}=J_{I I}^{2}=\frac{1-v}{E} K_{I I}^{2}
\end{gathered}
$$


Stress field in the crack front vicinity

The stress field in $2 \mathrm{D}$ in the vicinity of the crack front, were proposed by Tada et al. [22] by the general equation:

$$
\sigma_{i, j}^{I, I I}(r, \theta)=\frac{K_{I, I I}}{\sqrt{2 \pi r}} f_{i, j(\theta)}
$$

Fig.2 shows the stress field near a crack point with the polar coordinates $(r, \theta)$. In addition, Eqn. (11) which is illustrates the constraints on the two axes ( $\mathrm{x}$ and $\mathrm{y}$ ).
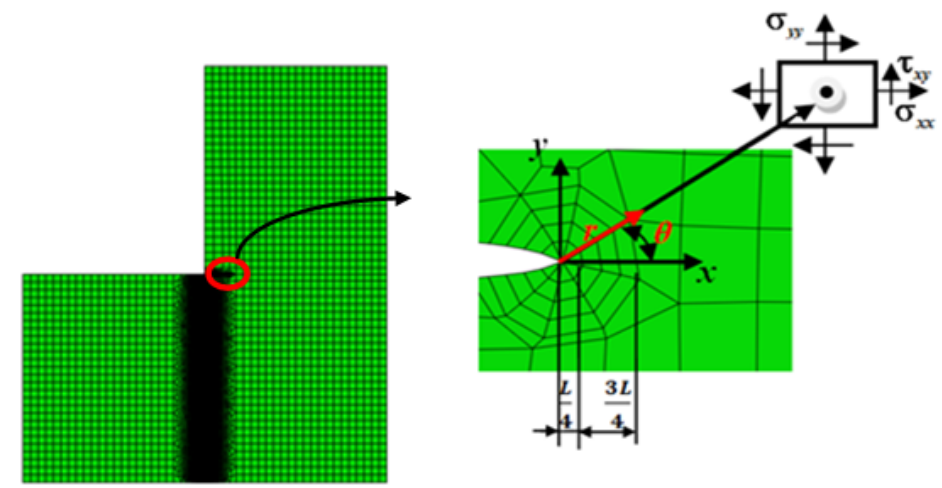

Figure 2: Stress field in the crack front vicinity

$$
\begin{aligned}
& \sigma_{x x}=\frac{K_{I}}{\sqrt{2 \pi r}} \cos \frac{\theta}{2}\left(1-\sin \frac{\theta}{2} \sin \frac{3 \theta}{2}\right) \\
& \sigma_{y y}=\frac{K_{I}}{\sqrt{2 \pi r}} \cos \frac{\theta}{2}\left(1+\sin \frac{\theta}{2} \sin \frac{3 \theta}{2}\right) \\
& \tau_{x y}=\frac{K_{I}}{\sqrt{2 \pi r}} \sin \frac{\theta}{2} \cos \frac{\theta}{2} \cos \frac{3 \theta}{2}
\end{aligned}
$$

\section{Singularity zone in modeling}

We have chosen CPE4R type elements for the modeling by Abaqus. This type of element is used for 2D models. A reduced integration element (CPE4R) two-dimensional plane strain quadrilateral at 4 nodes (bilinear). This type of element is well suited for simulation. Thus, one uses singular elements around the front of the crack. The types of these singular "quarter point" elements are collapsed quadratic elements.

The mesh around the zone of singularity is refined according to the number of the contour, thus according to the size of the crack front.



(a)

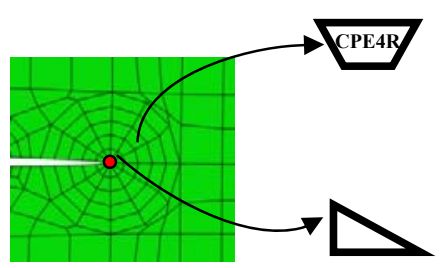

(b)

Figure 3: Collapsed quadrilateral element to obtain a triangular element b)The elements chosen types for modeling around of tow cracks tips. 


\section{FRETTING FATIGUE}

\section{Different geometric configurations used in fatigue fretting}

10 apply the contact stress, three types of counter-body are generally used (Fig. 4). The sphere/plane contact is preferred in the study of wear because it is easy to implement and facilitates the comparison with the pion-disc contact. The cylinder/plane contact is more often linked to the study of cracking because we can then formalize the loading in two dimensions and model it by finite elements. The plane/plane contact is used more and more. By varying the radius of curvature of the edges of the counter-body (zero for a straight edge), the contact pressure profile can be adjusted and thus more easily approach a real situation.

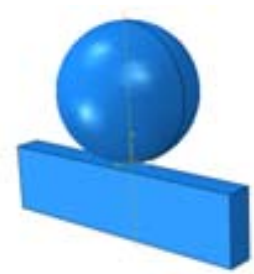

Sphere-Plane



Cylinder-Plane Plane-Plane

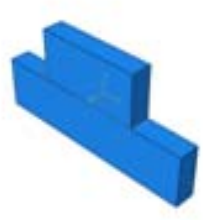

Figure 4: Different geometric configurations used for fretting tests.

\section{Coefficient of friction (COF)}

The coefficient of friction, $\mu$, is a measure of the amount of friction that exists between two surfaces. A low value of the coefficient of friction indicates that the force required for sliding to occur is less than the force required when the coefficient of friction is high. The value of the coefficient of friction is given by:

$$
\mu=\frac{\text { Frictional }- \text { force }}{\text { normal }- \text { force }}
$$

The transposition gives: friction force $=\mu \times$ normal force. The friction coefficient is the ratio of a force to a force and therefore has no units Bird and Chivers [23].

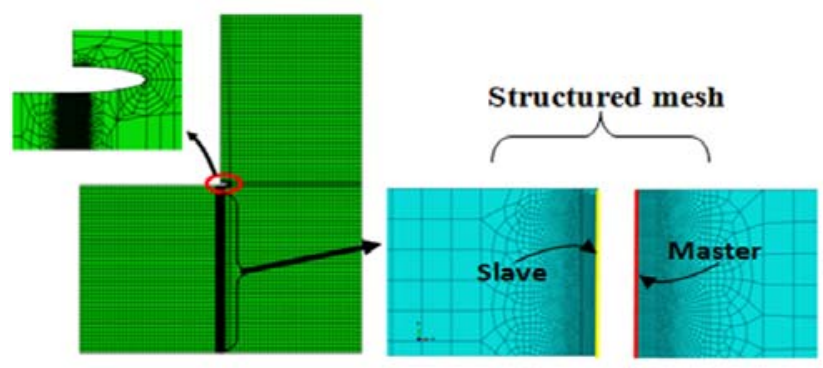

(a)



(b)

Figure 5: Model to model fretting fatigue and initial cracking; a) Slave-Master model of fretting fatigue; b) boundary conditions and dimensions of model.

\section{NUMERICAL MODEL FOR MODELING}

I $\mathrm{n}$ our model, the dimensions of the mesh are: height $\mathrm{B}=8 \mathrm{~mm}$ and width $\mathrm{C}=\mathrm{D}=7 \mathrm{~mm}$, the length of the horizontal crack has dimensions $\mathrm{a}=0.1,0.5$, and $1 \mathrm{~mm}$. A 4-node (bilinear) two-dimensional plane strain quadrilateral reduced integration element (CPE4R) was used around the contact zone (fretting fatigue). The number of elements 
of this model is 180436 and the number of nodes is 183916. Coefficients of friction (COF) of 0.1, 0.3 and 0.6, were used in this study. The steel structure, the elastic material parameters are $\mathrm{E}=72.10 \mathrm{GPa}$ and $\nu=0.3$. The structure is subjected to uniform tensile stress, normal load, the pressure load were considered $\sigma=100 \mathrm{MPa}, 50 \mathrm{~N}$ and $50 \mathrm{~N}$, respectively, the fixed support was applied to the lower surface of the structure. The crack is inclined by the angle $\alpha=15^{\circ}, 30^{\circ}$ and $45^{\circ}$.

\section{RESULTS AND DISCUSSIONS}

$\mathrm{T}$ he variation of the stress intensity factor as a function of $(\mathrm{a} / \mathrm{w})$ is shown in (Fig. 6). From this comparison, we show that the value of $\mathrm{K}_{\mathrm{I}}$ is much higher than that of $\mathrm{K}_{\text {III }}$. For the modeling of the problems in fretting fatigue, these comparisons are confirmed by numerous studies Kimura and Sato [24], Cho [25], Giner et al [1] and as a function of the crack length have been presented by Pitta et al [26], Hoijati et al [27] and Ackiel et al [28]. Thus, these results were confirmed by Nandish et al [29] on crack propagation. Indeed, Kimura and Sato [24] obtained that the stress intensity factor $\mathrm{K}_{\mathrm{I}}$ in fatigue by fretting has higher values compared to the study without fretting.

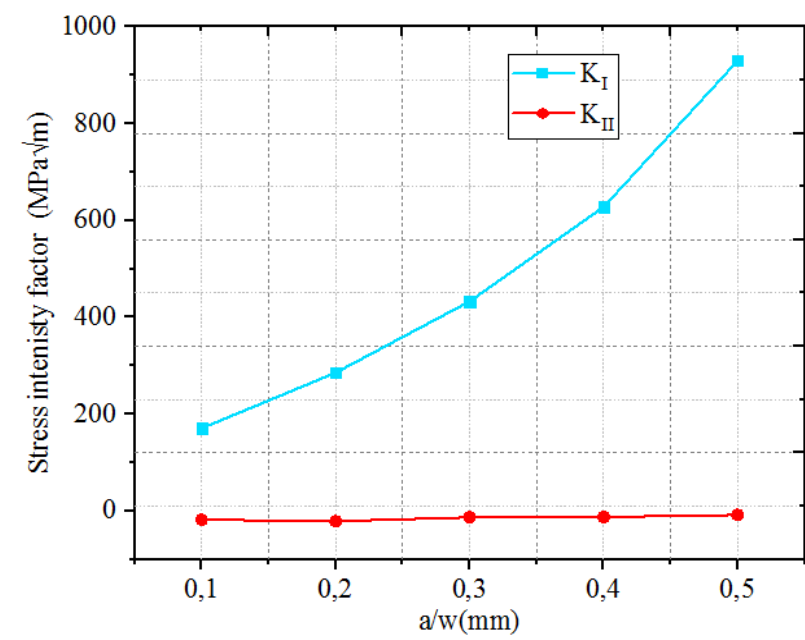

a)

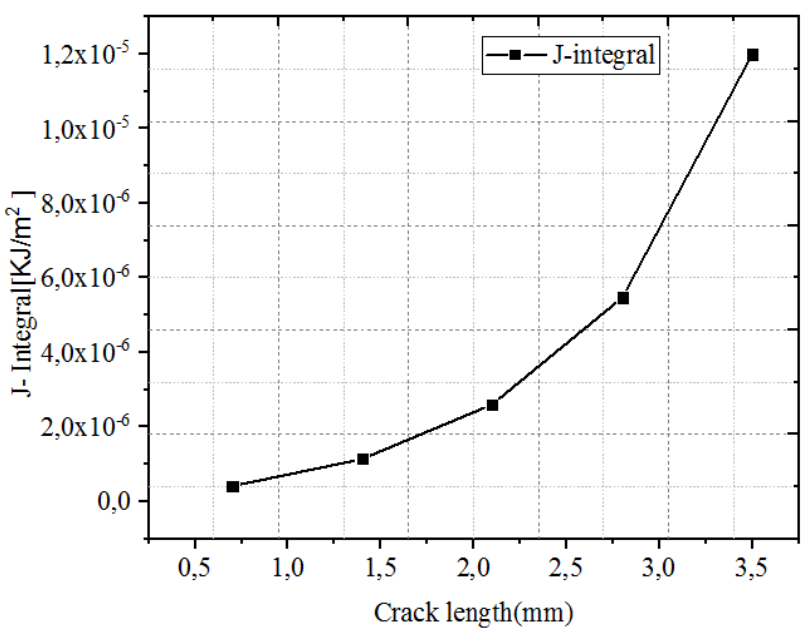

b)

Figure 6: The variation of the SIF factor along the ratio (a/w) a); and b)The variation of the (J) in function of crack length.

\section{Fretting fatigue from a horizontal crack}

The figure below presents the model in contact with fretting fatigue in detail, in precision the contact surface. Thus, the boundary conditions of a horizontal crack of $\alpha=0^{\circ}$.

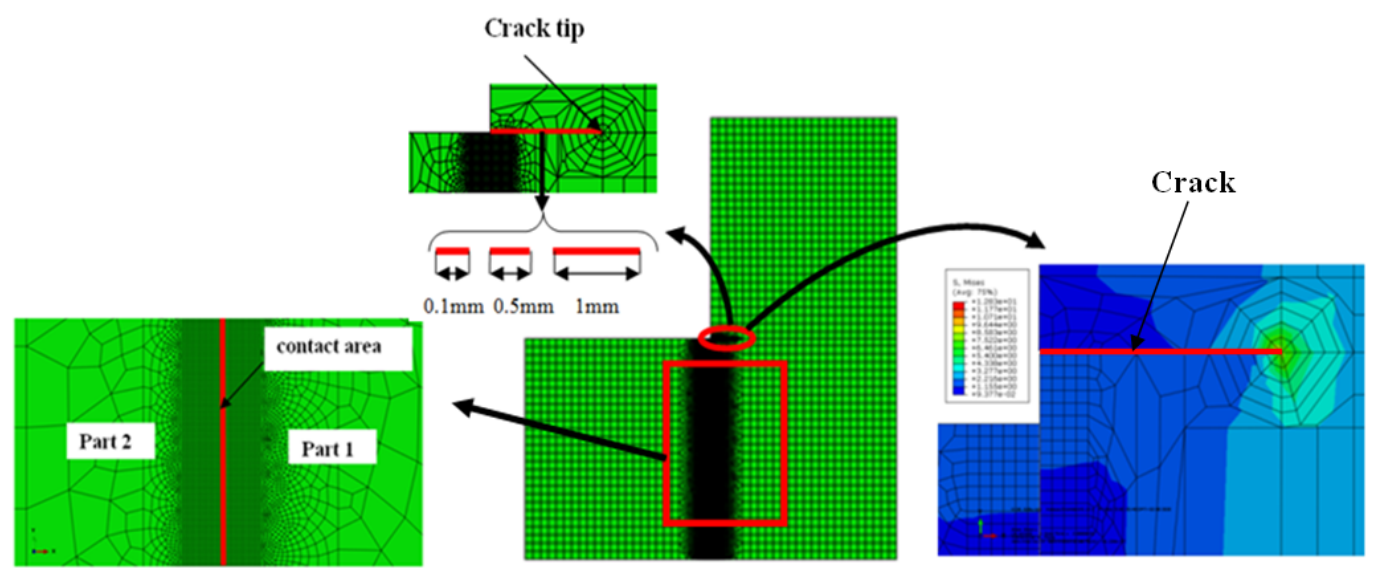

Figure7: FEM model and contact zone in the case $\alpha=0^{\circ}$. 


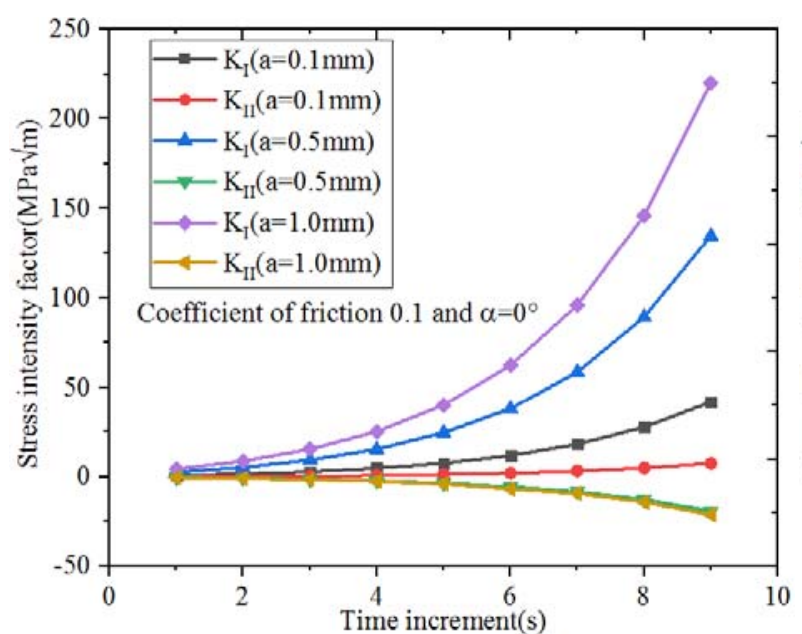

a)

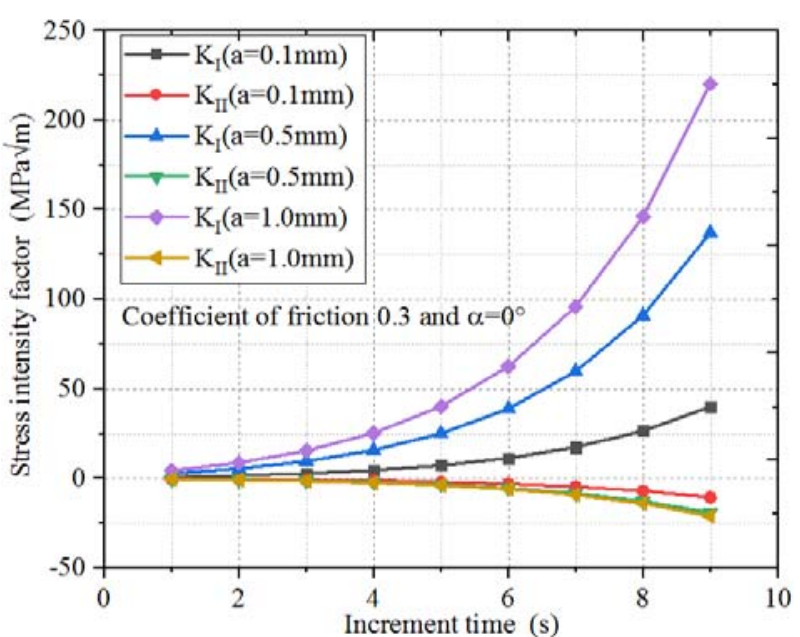

b)

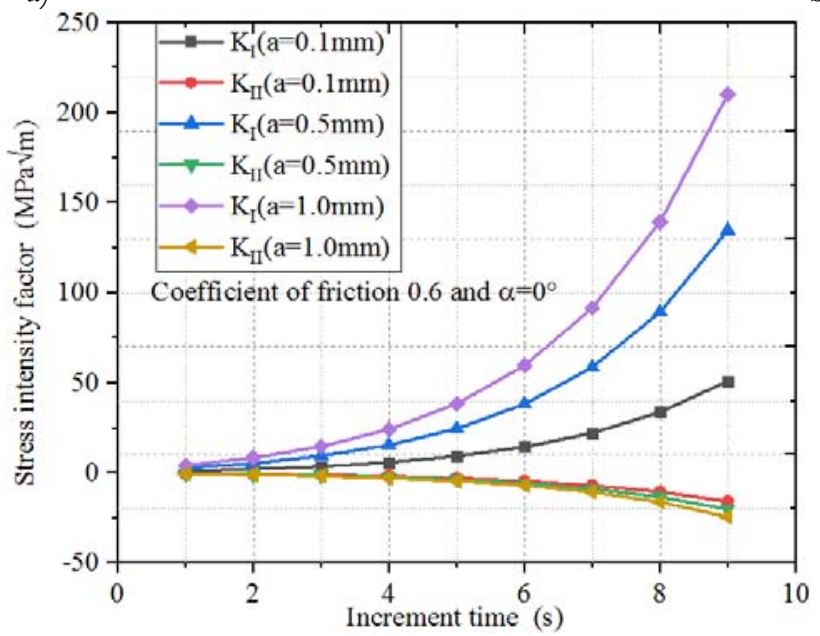

c)

Figure 8: The evolution of the FIC as a function of time increment with COF a) 0.1, b) 0.3 and c) $0.6 \alpha=0^{\circ}$.

The variation of the stress intensity factor as a function of the increment of the cracking time in fretting fatigue, for the model studied is presented on Fig. 8. One uses the various crack lengths (a) $=0.1,0.5$ and 1.0 mm and coefficient of friction 0.6 for the problem of fritting fatigue. Indeed, we notice that the increase in the time increment causes an increase in $K_{I}$, and a decrease in $K_{I I}$ of the same length and the same coefficient of friction. In addition, the increase in the coefficient of friction in the studied case $\alpha=0^{\circ}$ causes a decrease in $\mathrm{K}_{\mathrm{I}}$ and $\mathrm{K}_{\mathrm{II}}$. These results were obtained by Sallam et al [30] in the case of the effects of the coefficient of friction on the stress intensity factor concerning the $\mathrm{K}_{\mathrm{I}}$. The rate of increase of $\mathrm{K}_{\mathrm{II}}$ is small compared to $\mathrm{K}_{\mathrm{I}}$.

Fig. 9 shows the evolution of the integral of the contour $(J)$ as a function of the time increment for the cases of $\mathrm{COF}=$ $0.1,0.3$ and 0.6 between the three cases of lengths $\mathrm{a}=0.1,0.5$ and $01 \mathrm{~mm}$, at from this comparison. The first three values are almost zero and linear. It can also be observed that, with the increase of the time increment, there is an increase in (J) of the same length and the same coefficient of friction from the third time increment. However, there is a decrease in the results of $(J)$ for different friction coefficients between them.

\section{Fretting fatigue from an inclined crack}

The following model shows the fatigue fretting of two parts in contact with each other and contains a crack inclined by the angle $\alpha=15^{\circ}, 30^{\circ}$ and $45^{\circ}$ with a coefficient of friction 0.6.

The SIF evolution as a function of the time increment with a friction coefficient 0.6 is indicated in (Fig.11). This comparison is carried out on the different crack lengths for a $=0.1,0.5$ and $01 \mathrm{~mm}$ and the angle inclination $\alpha=15^{\circ}$ (Fig.11a), $\alpha=30^{\circ}$ (Fig.11b) and $\alpha=45^{\circ}$ (Fig.11c) for the fretting fatigue model. In addition, the increase in the increment time causes a decrease in $\mathrm{K}_{\mathrm{I}}$ and an increase in $\mathrm{K}_{\mathrm{II}}$ on the contrary for the comparison of the results obtained 
for $\alpha=0^{\circ}$. However, the value of $\mathrm{K}_{\mathrm{II}}$ is almost linear is equal to 0 in the case of $(\mathrm{a}=0.1 \mathrm{~mm})$ with $\left(\alpha=15^{\circ}\right)$, but $\mathrm{K}_{\text {II }}$ less than $(0)$ in the case of $\mathrm{a}=0.5 \mathrm{~mm}$ with $\left(\alpha=45^{\circ}\right)$. Moreover, the results obtained from FIC are proportional to the crack length.



a)

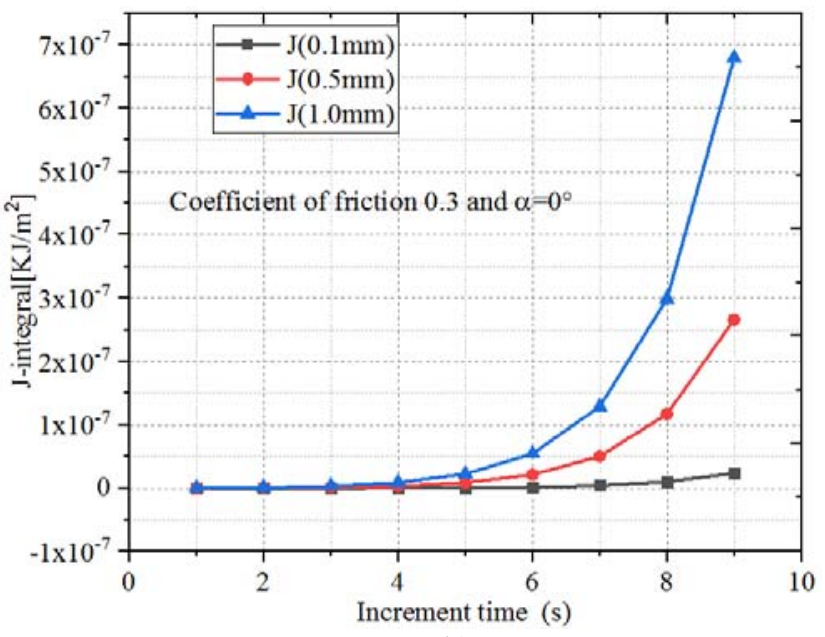

b)

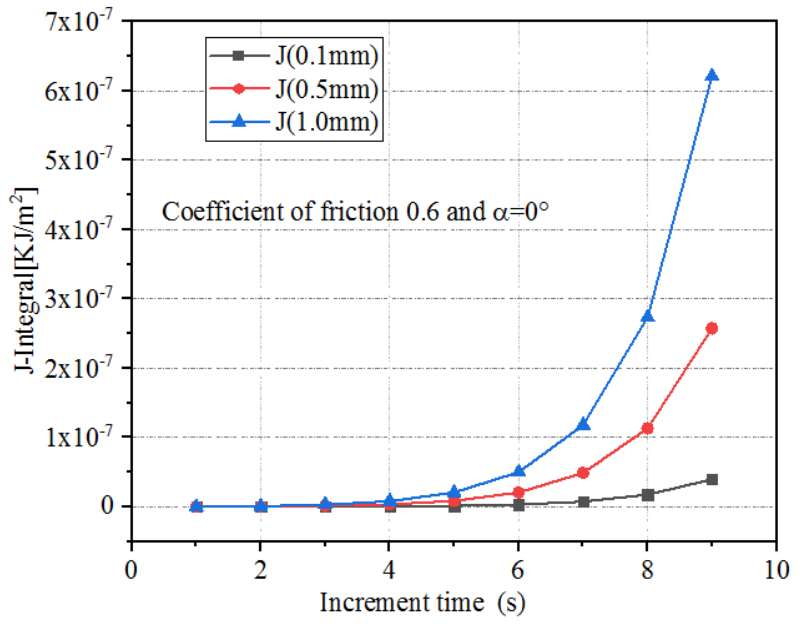

c)

Figure 9: The evolution of the integral of the contour $(J)$ as a function of time increment with COF a) $0.1, b) 0.3$ and c) $0.6 \alpha=0^{\circ}$.

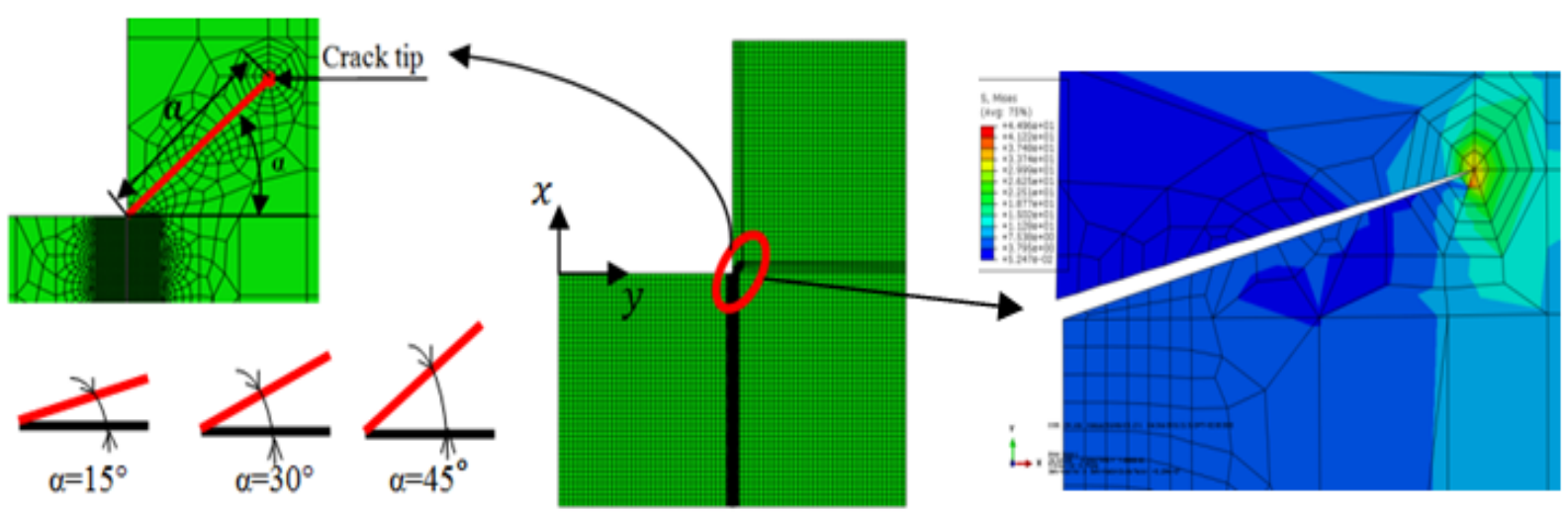

Figure10: Fretting fatigue model with an initial inclined crack $\alpha=15^{\circ}, 30^{\circ}$ and $45^{\circ}$. 


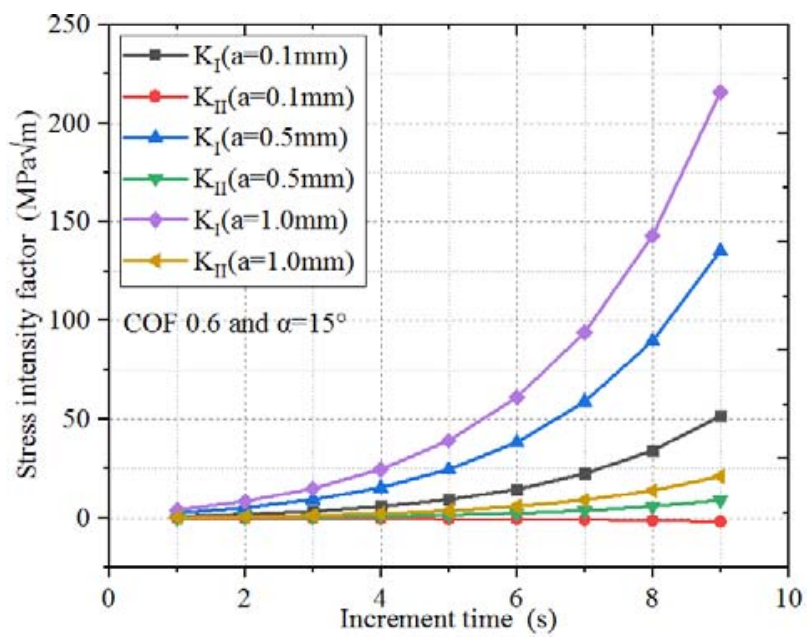

a)



b)



c)

Fig. 11: The evolution of the FIC as a function of time increment with COF 0.6 and $\alpha=15^{\circ}, 30^{\circ}$ and $45^{\circ}$.

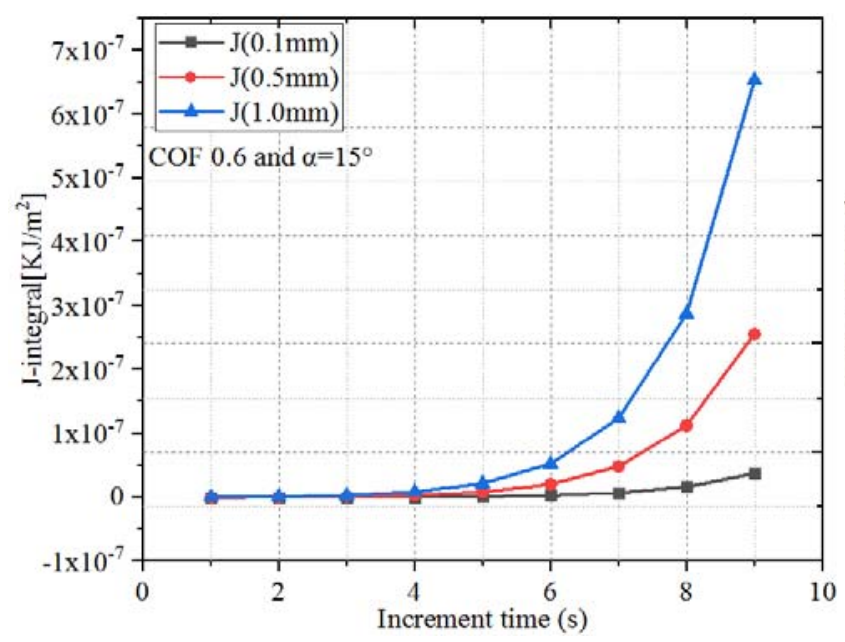

a)



b) 


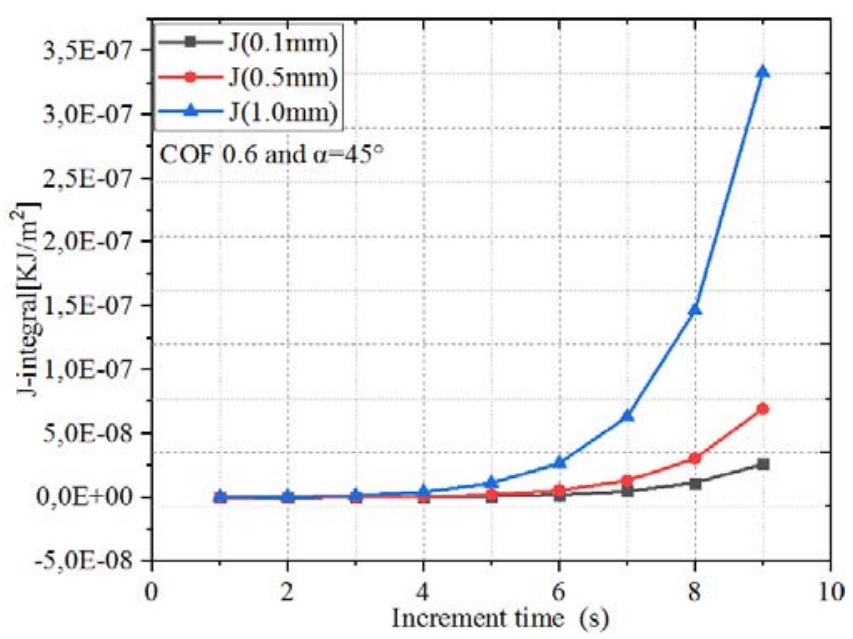

c)

Figure 12: The evolution of the integral of the contour $(\mathbf{J})$ as a function of time increment with COF 0.6 and $\alpha=15^{\circ}, 30^{\circ}$ and $45^{\circ}$.

Fig. 12 shows the evolution of the FIC as a function of time increment with a friction coefficient 0.6 and the angle of inclination $\alpha=15^{\circ}$ (Fig. 12a), $\alpha=30^{\circ}$ (Fig. 12b) and $\alpha=45^{\circ}$ (Fig.12c), the values of (J) are proportional to the crack length.However, increasing the time of the increment causes an increase in $(\mathrm{J})$ in all three cases of the crack length. The value of $(J)$ is increased by increasing the time increment and the tilt angle $\alpha$. The tables below explain the different results of comparison between the angles of inclination and the crack length concerning the SIF (Tab. 1). Tab. 2 shows the results of the integral of the contour $(\mathrm{J})$.

\begin{tabular}{cccccccccc}
\hline & \multicolumn{2}{c}{$\alpha=0^{\circ}$} & \multicolumn{2}{c}{$\alpha=15^{\circ}$} & \multicolumn{2}{c}{$\alpha=30^{\circ}$} & \multicolumn{3}{c}{$\alpha=45^{\circ}$} \\
$a$ & $\mathrm{~K}_{\mathrm{I}}$ & $\mathrm{K}_{\mathrm{II}}$ & $\mathrm{K}_{\mathrm{I}}$ & $\mathrm{K}_{\mathrm{II}}$ & $\mathrm{K}_{\mathrm{I}}$ & $\mathrm{K}_{\text {II }}$ & $\mathrm{K}_{\mathrm{I}}$ & $\mathrm{K}_{\text {II }}$ \\
0.1 & 51.96 & -15.83 & 51.74 & -1.654 & 50.85 & 11.39 & 41.04 & 14.04 \\
0.5 & 136.7 & -20.12 & 135.3 & 9.121 & 122.4 & 32.90 & 69.98 & 48.97 \\
1.0 & 216.1 & -24.35 & 215.8 & 21.21 & 184.4 & 54.39 & 138.2 & 70.03 \\
\hline
\end{tabular}

Table1: The different results of SIF comparisons between tilt angles and crack length.

\begin{tabular}{ccccc}
\hline & $\alpha=0^{\circ}$ & $\alpha=15^{\circ}$ & $\alpha=30^{\circ}$ & $\alpha=45^{\circ}$ \\
$a$ & $\mathrm{~J}$ & $\mathrm{~J}$ & $\mathrm{~J}$ & $\mathrm{~J}$ \\
0.1 & $3.9551 \mathrm{E}-08$ & $3.7222 \mathrm{E}-08$ & $3.7717 \mathrm{E}-08$ & $2.6127 \mathrm{E}-08$ \\
0.5 & $2.5744 \mathrm{E}-07$ & $2.5544 \mathrm{E}-07$ & $2.2318 \mathrm{E}-07$ & $6.9398 \mathrm{E}-08$ \\
1.0 & $6.2125 \mathrm{E}-07$ & $6.5278 \mathrm{E}-07$ & $5.1345 \mathrm{E}-07$ & $3.3319 \mathrm{E}-07$ \\
\hline
\end{tabular}

Table2:Different results of comparison of the integral of the contour $(J)$ between the angles of inclinationand the crack length. 


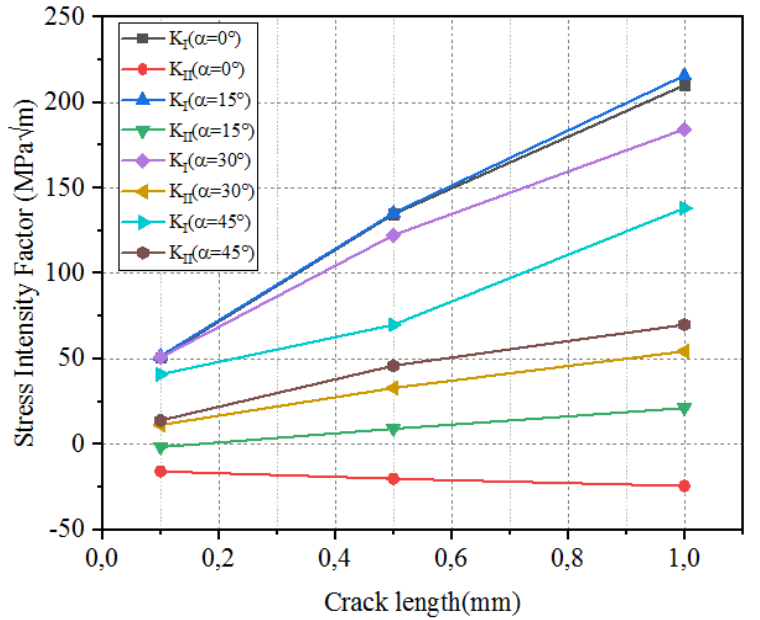

a)

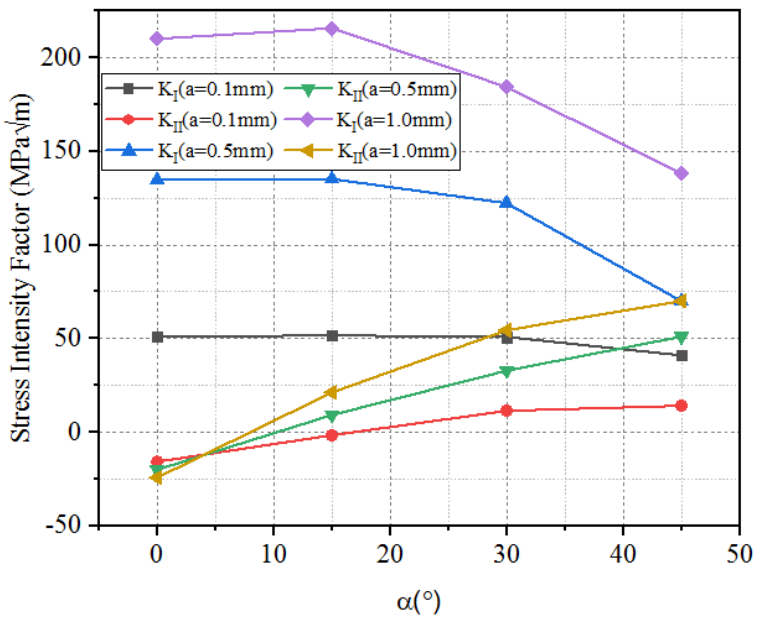

b)

Figure 13: SIF evolution: a)as a function of the crack length (a);b) as a function of the angle $(\alpha)$

Fig. 13 shows the evolution of the stress intensity factor (SIF) as a function of the length of the crack in Fig. (13a) and as a function of the angle $(\alpha)$ in Fig. (13b).In addition, the angle of the crack $\alpha$ increases $\mathrm{K}_{\mathrm{I}}$ decreases for the same $\alpha$ as the length of the crack increases.Fayed [31] justified that $\mathrm{K}_{\mathrm{I}}$ increases for higher crack tilt angles, i.e. $\alpha>60^{\circ}$ and the rate of increase of $\mathrm{K}_{\mathrm{II}}$ is relatively low when the ratio $(\mathrm{a} / \mathrm{w})$ increases.

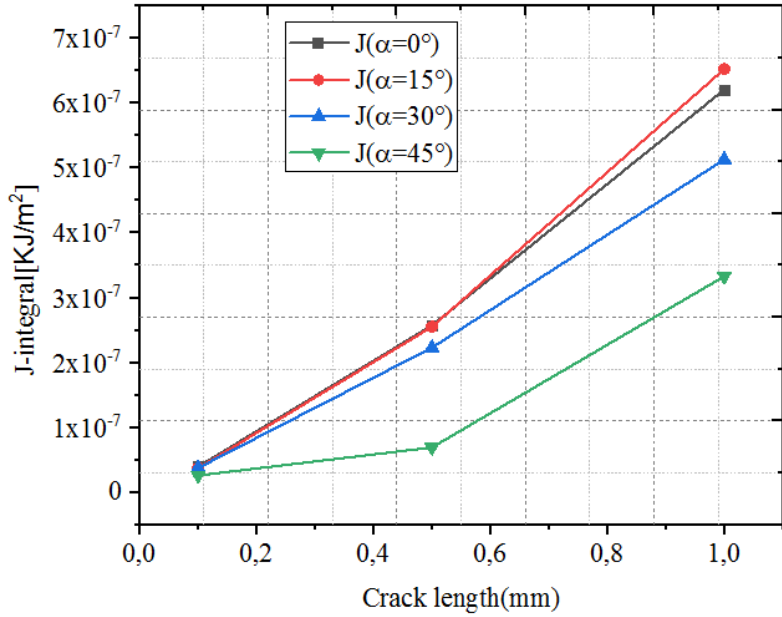

a)

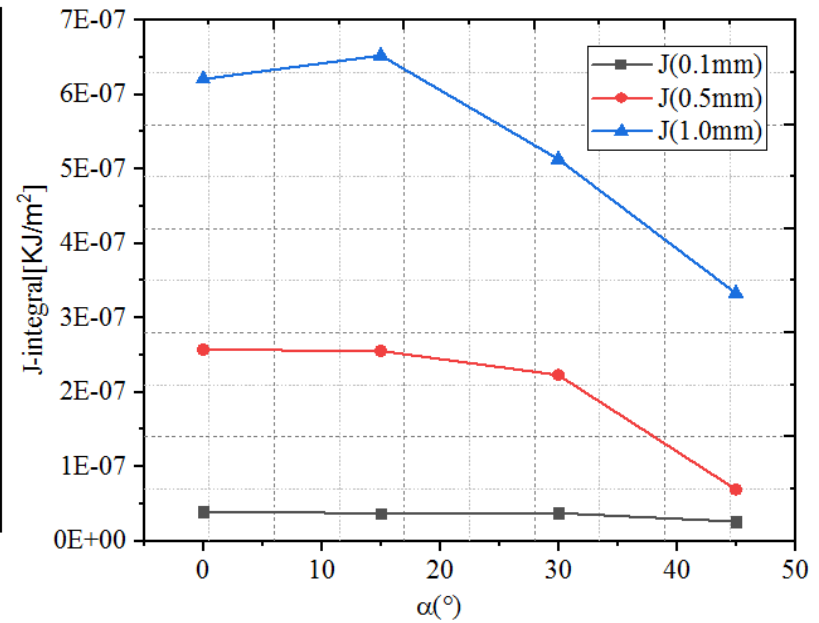

b)

Figure 14: The evolution of the integral of the contour J: a) as a function of the crack length (a);b) as a function of the angle ( $\alpha$ ).

Fig. 14 shows the integral of the contour (J) as a function of the crack length in Fig. (14a) and as a function of the angle $(\alpha)$ in Fig. (14b) for different crack lengths (a).The increase in crack length causes an increase in (J), these forms of results were obtained by Margi et al [32].In addition, the results obtained are proportional, and the increase in the angle ( $\alpha$ ) Fig. (14b) causes a decrease in $(J)$ in all cases of the crack length. The low rate of decrease of $(J)$ for the low crack length a $=$ $0.1 \mathrm{~mm}$ is high for $\mathrm{a}=0.5 \mathrm{~mm}$ and $1.0 \mathrm{~mm}$. Especially from $\alpha>20^{\circ}$.

\section{CONCLUSION}

wo cases of fretting fatigue were studied, firstly the contact in fretting fatigue concerning a horizontal crack and the other study based on an inclined crack for different values of angles $\alpha=15^{\circ}, 30^{\circ}$ and $45^{\circ}$. The finite element method was used to model the contact between the two parts. It is observed that with the increase of the time increment of the load the integral of the contour J increases, for the different cases of the angle of inclination of the crack. 
The results obtained in our work justified, that the effects of contact to influence important on the parameters of crack. Thus, the low value of $(\mathrm{COF})$ gives results of stress intensity factor $\left(\mathrm{K}_{\mathrm{I}}\right)$ in mode $\mathrm{I}$ higher in fretting fatigue. The results obtained show that the coefficient of friction of a low value causes a time is higher compared to a higher coefficient of friction for the case of a rectilinear crack of $\alpha=0^{\circ}$. There is a proportionality between the results obtained from FIC and the integral of the contour $(\mathrm{J})$ as a function of the time increment of the load in fretting fatigue.

\section{REFERENCES}

[1] Pereira, K. Libardo V. Vanegas-Useche and M. A. Wahab, (2020). Aspects of Fretting Fatigue Finite Element Modelling Computers, Materials \& Continua CMC, 64(1), pp.97-144.

[2] Hojjati-Talemi, R., Wahab, M. A.,Giner, E.,Sabsabi, M. (2013). Numerical Estimation of Fretting Fatigue Lifetime Using Damage and Fracture Mechanicsv 52, pp. 11-25.DOI:10.1007/s11249-013-0189-8.

[3] Julien, S., Siegfried, F., Georges, C., Christine, Y.and Fikri, H. (2020). Shear driven crack arrest investigation under compressive state prediction of fretting fatigue failure of aluminium strands, International Journal of Fatigue, 136, 105589. DOI: $10.1016 /$ j.ijfatigue.2020.105589.

[4] Thanh, Q. N., Hieu, C.D., Luan. C. V., Nguyen, H. X. and Nhi, K.N. (2020). Fretting Fatigue Damage Nucleation and Propagation Lifetime Using a Central Point Movement of Power Spectral Density, Shock and Vibration, 4985134, DOI: $10.1155 / 2020 / 4985134$

[5] Nadeem, A. B. and Magd, A.W. (2017). Finite element analysis of fretting fatigue under out of phase loading conditions,Materials Science, DOI:10.1016/j.triboint.2017.01.022

[6] Qingming, D., Nadeem, B., Xiaochun, Y. and Magd, A.W. (2018). Numerical Modeling of the Effect of Randomly Distributed Inclusions on Fretting Fatigue-Induced Stress in Metals, metals, 8, 836. DOI:10.3390/met8100836.

[7] Antti, M., Janne, J., Jouko, H., Tero, F. and Arto, L.(2020). FEM-based wear simulation for fretting contacts, Rakenteiden Mekaniikka, Journal of Structural Mechanics, 53(1), pp.20-27, DOI: 10.23998/rm.76261.

[8] Tongyan, Y. and Magd, A. W.(2017). Finite element analysis of fretting wear under variable coefficient of friction and different contact regimes, Tribology International, 107, pp. 274-282. DOI: 10.1016/j.triboint.2016.11.044.

[9] Antti, M., Jussi, G., Anton, L. and Tero, F. (2017). arge bore engine connecting rod fretting analysis RakenteidenMekaniikka, Journal of Structural Mechanics, 50(3), pp.239-243. DOI: 10.23998/rm.64914.

[10]Jouko, H., Arto L. and Antti, M. (2016).Third Particle Ejection Effects on Wear with Quenched and Tempered Steel Fretting Contact, JournalTribology Transactions, 60(11), pp. 70-78. DOI: 10.1080/10402004.2016.1146813.

[11] Wijesuriya, H.S. and Mallikarachchi, H.M.Y.C. (2018). Predicting Fretting Fatigue Crack Propagation Using Finite Element Analysis,Moratuwa Engineering Research Conference (MERCon). DOI: $10.1109 /$ MERCon.2018.84218862018.

[12] Wang, S.and Abdel Wahab, M. (2020) Effect of Loading Conditions in Fretting Fatigue on Wear Characteristics, Proceedings of the 13th International Conference on Damage Assessment of Structures.

[13] Chen, H., Dasheng, W., Yanrong, W. and Xianghua, J. (2019). Introduction of fretting-contact-induced crack closure: Numerical simulation of crack initiation and growth path in disk/blade attachment, Chinese Journal of Aeronautics, 32,(8), pp 1923-1932. DOI: 10.1016/j.cja.2019.04.011.

[14] Nitikorn, N., Anchalee, M. and Chaosuan, K. (2017). Fretting Fatigue with Cylindrical-On-Flat Contact: Crack Nucleation, Crack Path and Fatigue Life, Materials(Basel), 10(2). DOI: 10.3390/ma10020155.

[15] Erdogan, F. and Sih, G.C. (1963).On the crack extension in plates under plane loading and transverse shear, Journal of Basic Engineering, 85, 19-527.

[16] Saverio, F. (2014) Modélisation tridimensionnelle de la fermeture induite par plasticité lors de la propagation d'une fissure de fatigue dans l'acier 304L thèse de doctorat, l'école nationale supérieure de mécanique et d'aérotechnique.

[17] Rice, J.R. (1968). A path independent integral and the approximate analysis of strain concentrations by notches and cracks. J. of Appl. Mech., 35, pp.379-386.

[18] Bui, H.D. (1973). Dualité entre les intégrales de contour. Compte Rendu Acad. Sciences, T. 276, Paris.

[19] Nguyen, Q.S. (1980). Méthodes énergétiques en mécanique de la rupture. J. de Méca.,19(2), pp. 363-386.

[20] Destuynder, Ph. and Djaoua, M. (1981). Sur une interprétation mathématique de l'intégrale de Rice en théorie de la rupture fragile, Math. Meth. In the Appl. Sci., 3, pp. 70-87.

[21] Tran, A. T. (2011). Etude du delaminage en mode II de composites unidirectionnels soumis a des sollications rapides, approche globale et approche locale, Ph.D. Thesis, Ecole doctorale n 432 : Sciences des Métiers de l’ingénieur Paris. 
[22] Tada, H.P., Paris, P.C. and Irwin, G.R. (2000). The Stress Analysis of Cracks Handbook, American Society of Mechanical Engineering.

[23] Bird, J. O., Chivers, P. J . (1993). Friction, Newnes Engineering and Physical Science Pocket Book, pp. 235-237.

[24] Kimura, T. and Sato, K. (1999) Stress intensity factors for oblique cracks in fretting fatigue Transactions on Engineering Sciences, 24.

[25] Cho, J.R. (2014). Stress Intensity Factor Calculation for 2-D Cracked Bodies by Petrov-Galerkin Natural Element Method Advences in civil En vironmental, and Materiels Research (ACEM14) Busan, Korea.

[26] Pitta, S.,Rojas,J. I. and Crespo,D. (2017). Comparison of fatigue crack growth of riveted and bonded aircraftlap joints made of Aluminium alloy 2024-T3 substrates - A numerical study, 6th International Conference on Fracture Fatigue and Wear, IOP Conf. Series: Journal of Physics: Conf. Series 843- 012035.

[27] Hojjati, T.R.and Abdel Wahab, M. (2012). XFEM for fretting fatigue: straight VS mixed mode crack propagation Journal Carpinteri A, Iacoviello F, Pook LP, Susmel L, eds Proceedings of the 4th International Conference on Crack Paths, Gaeta, Italy, pp. 351-358.

[28] Mohamed, M.A. Manurung, Y.H.P., Ghazali,F.A. and Karim,A.A. (2015).Finite Element-Based Fatigue Life Prediction Of A Loadcarrying Cruciform Joint, Journal of Mechanical Engineering and Sciences (JMES) 8, pp. 1414-1425. DOI: 10.15282/jmes.8.2015.16.0138.

[29] Nandish, R. V., NiranjanPattar, Raja Reddy, C V., Vizhian, S. P. and Ramachandra, S. (2013).Computational Analysis Of Stress- Intensity Factors For A Single-Edgenotch Tension Specimen By Astress Function Int. J. Mech. Eng. \&Rob. Res. 2(4).

[30] Sallam, H.E.M., Sisi, A.E.A. El. and Matar, E.B. (2011). Effect of clamping force and friction coefficient on stress intensity factorof cracked lapped joints, Engineering Failure Analysis, 18, pp. 1550-1558.

[31] Fayed, A. S. (2017). Numerical analysis of mixed mode I/II stress intensity factors of edge slant cracked plates Engineering Solid Mechanics pp. 61-70.

[32] Margi, G., Himanshu, P. and Sachin, K. (2020). Elasto-Plastic Fracture Modeling for Crack Interaction with XFEMTransactions of the Indian Institute of Metals 73, pp. 1679-1687. 